
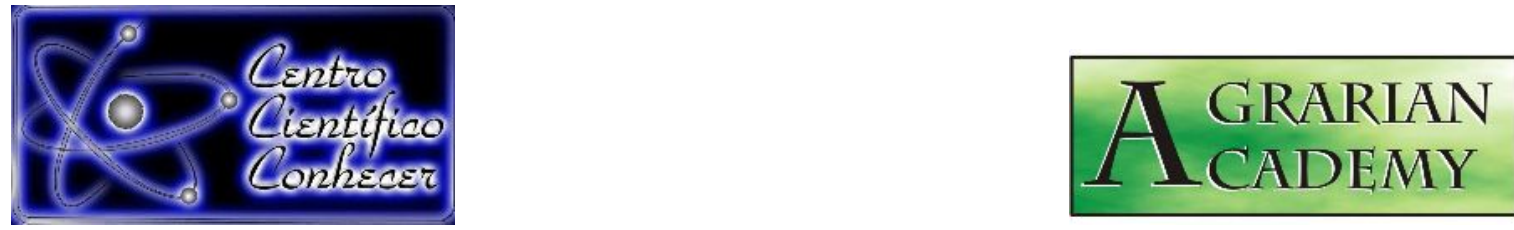

\title{
DESEMPENHO AGRONÔMICO DO COENTRO EM FUNÇÃO DA DENSIDADE DE SEMEADURA E DIRECIONAMENTO DAS LINHAS DE PLANTIO NO CANTEIRO
}

\footnotetext{
Jucivânia Cordeiro Pinheiro ${ }^{1}$, Leandro Alves Pinto ${ }^{1}$, Cicero Cordeiro Pinheiro Francisco Edson da Silva ${ }^{2}$, Felipe Thomaz da Camara ${ }^{3}$

1- Discente do Curso de Agronomia da Universidade Federal do Cariri - UFCA, Crato, Ceará, Brasil. Email: jucivaniacordeiro98@gmail.com

2. Mestrando do Programa de Pós-graduação em Ciências do Solo da Universidade Federal da Paraíba - UFPB, Areia, Paraíba, Brasil

3. Professor Doutor do curso de Agronomia da Universidade Federal do Cariri - UFCA, Crato, Ceará, Brasil

Recebido em: 02/06/2019 - Aprovado em: 15/06/2019 - Publicado em: 22/07/2019 DOI: 10.18677/Agrarian_Academy_2019a34
}

\begin{abstract}
RESUMO
O coentro (Coriandrum sativum L.) é uma hortaliça folhosa de grande valor comercial no Brasil, entre os produtores da região nordeste a cultivar Verdão é bastante explorada para produção de folhas verdes. Embora a cultura tenha grande importância, a escassez de informações a respeito da produção e comercialização do coentro é um problema. O experimento foi conduzido no Centro de Ciências Agrárias e da Biodiversidade (CCAB) da Universidade Federal do Cariri (UFCA), com o objetivo de avaliar o efeito da quantidade de sementes plantadas e direcionamento das linhas de cultivo na produtividade do coentro Verdão. O delineamento experimental utilizado foi em blocos ao acaso, com os tratamentos em arranjo fatorial $4 \times 2$, correspondendo a quatro densidades de semeadura $(1,2,3,4$ $\mathrm{g} \mathrm{m}^{-2}$ de sementes), e dois direcionamentos no canteiro (Norte-Sul, Leste-Oeste) com três repetições. Foram avaliadas: altura das plantas; número de plantas por metro quadrado (NP), massa fresca da parte área (MFPA); produtividade e massa de raiz por metro quadrado (MFR). A análise estatística dos dados foi realizada com auxílio do programa SISVAR 5.3 (FERREIRA, 2011). Os resultados foram submetidos a análise de variância e análise de regressão. As variáveis que apresentaram diferença significativa foram avaliadas pelo teste de Tukey a $5 \%$. As linhas de cultivo no canteiro no sentido norte-sul mostraram ser mais vantajosas para obter plantas com maior altura e maior quantidade de MFPA, mas não mostrou diferença na produtividade de MFPA $/ \mathrm{m}^{2}$, entretanto mais estudos são necessários para esclarecer seu efeito no incremento da produtividade do coentro.
\end{abstract}

PALAVRAS-CHAVE: Coriandrum sativum L., Folhosa, Produtividade 


\title{
AGRONOMIC PERFORMANCE OF CORIANDER IN FUNCTION OF THE DENSITY OF SOWING AND DIRECTING OF THE PLANTING LINES IN THE BED
}

\begin{abstract}
The coriander (Coriandrum sativum $\mathrm{L}$ ) is a hardwood vegetable of great commercial value in Brazil, among the producers of the northeast region the cultivar Verdão is widely exploited to produce green leaves. Although culture is of great importance, the scarcity of information about the production and commercialization of coriander is a problem. The experiment was conducted at the Center of Agricultural Sciences and Biodiversity (CCAB) of the Federal University of Cariri (UFCA), with the objective of evaluating the effect of the number of seeds planted and the orientation of the crop lines on the productivity of Verdão. The experimental design was a randomized block design with $4 \times 2$ factorial treatments, corresponding to four sowing densities $(1,2,3,4$ $\mathrm{g} \mathrm{m}-2$ of seeds), and two orientations at the site (North-South, East-West) with three replicates. The following were evaluated: plant height; number of plants per square meter (NP), area fresh mass (MFPA); productivity and root mass per square meter (MFR). Statistical analysis of the data was performed using the SISVAR 5.3 program (FERREIRA, 2011). The results were submitted to analysis of variance and regression analysis. The variables that presented significant difference were evaluated by the Tukey test at $5 \%$. The cultivation lines at the north-south plot were more advantageous to obtain plants with higher height and higher amount of MFPA, but showed no difference in the productivity of MFPA $/ \mathrm{m}^{2}$, however more studies are needed to clarify its effect on the increase of coriander productivity.
\end{abstract}

KEYWORDS: Coriandrum sativum L., Hardwood, Productivity

\section{INTRODUÇÃO}

O coentro (Coriandrum sativum L.) planta herbácea anual, cuja altura varia de 25 a $60 \mathrm{~cm}$ é uma hortaliça folhosa de grande valor comercial no Brasil, sendo muito utilizada principalmente na culinária da região Nordeste onde grande número de agricultores familiares estão envolvidos na exploração para comercialização de folhas verdes (BOMFIM, 2017). Segundo Lopes et al. (2015) a cultura tem um aroma especial e um sabor marcante que combina muito bem com pescado, além de grande importância nutricional devido à presença de vitaminas $A, B 1, B 2$ e $C$, boa fonte de cálcio e ferro (SILVA; CHALCO, 2017). As sementes possuem características fitoterápicas e também são largamente comercializadas no Brasil.

Entre os produtores da região nordeste, a cultivar Verdão é a mais difundida e conhecida. É uma cultivar precoce, com ciclo de 30 a 40 dias. A planta é bastante vigorosa, com folhas de coloração verde-escura. Tem excelente rusticidade e boa resistência às doenças de folhagens (LIMA et al., 2007). Pereira et al. (2005) afirmam que pouca pesquisa tem sido feita com essa hortaliça, incluindo a tecnologia adequada para a produção, desenvolvimento de novas cultivares, dentre outras. Soma-se a isto, a escassez de informações a respeito da produção e comercialização do coentro. No Brasil o cultivo do coentro ainda é realizado, preferencialmente por semeadura direta manual e em canteiros, de forma orgânica, utilizando mão de obra familiar (MACIEL et al., 2012).

A produtividade da cultura é definida pela interação entre a planta, o ambiente de produção e o manejo adotado. Dentre as principais práticas de manejo que devem ser consideradas no cultivo das hortaliças está a densidade adequada de plantas por unidade de área, que afeta diretamente a produção da cultura do 
coentro, estando diretamente relacionada ao número de molhos ou maços por unidade de área, haja vista que esse número está relacionado ao número de plantas. A densidade de semeadura, apesar de ser uma técnica simples, pode aumentar a competição entre as plantas, sendo necessário o ajuste para melhorar a utilização de certos fatores de produção como: água, luz e nutrientes, para que não haja redução na qualidade e no rendimento do produto final (RESENDE et al., 2016).

Outro fator ambiental que pode determinar o desenvolvimento da cultura é a disposição das fileiras de cultivo em relação a orientação dos pontos cardeais e ao movimento relativo do sol resultando em maior ou menor interceptação da radiação solar pelas plantas, o que pode influenciar na produtividade final da cultura. A radiação solar sendo a fonte básica de energia nos processos fisiológicos e bioquímicos das plantas é, a principal variável ambiental, quando as exigências por água, nutrição e fitossanidade são satisfeitas (FERREIRA JUNIOR et al., 2014). Segundo Kappes (2010) a escolha adequada do arranjo de plantas pode favorecer a interceptação da radiação solar recebida pelas plantas, melhorando o aproveitamento da luz interceptada pela cultura e incrementando o crescimento vegetativo e o rendimento da produção. Portanto, a orientação das fileiras de plantio pode ser uma prática de manejo capaz de aumentar a produtividade sem elevar os custos de produção.

Tendo em vista a importância da determinação de densidades adequadas de plantio e da influência da radiação solar no desenvolvimento da cultura, objetivou-se avaliar o efeito da quantidade de sementes plantadas e do direcionamento das linhas de cultivo na produtividade do coentro verdão.

\section{MATERIAL E MÉTODOS}

A pesquisa foi realizada sob condições de campo na área experimental do Centro de Ciências Agrárias e da Biodiversidade (CCAB) da Universidade Federal do Cariri (UFCA), localizado no município de Crato - CE (7ำ14’2,4" S, 3922'10,6" W e altitude de $416 \mathrm{~m}$ ) no período de maio a junho de 2018.

O clima da região é classificado como Aw (KöPPEN, 1948), tropical úmido com estação seca no inverno e temperaturas elevadas, as quais variam, anualmente, entre 24 a $26^{\circ} \mathrm{C}$ e entre 26 a $30^{\circ} \mathrm{C}$, nos meses mais quentes. A precipitação média anual da região é 900 a 1000 mm, distribuída entre dezembro e maio. O solo é classificado como Argissolo vermelho Amarelo, de relevo suave ondulado e textura da camada superficial franco-arenosa. As características do solo da área experimental foram: $\mathrm{pH}(1: 2,5 \mathrm{H} 2 \mathrm{O})=4,3 ; \mathrm{P}\left(\right.$ Melich-1) $=7,0 \mathrm{mg} \mathrm{dm}^{-3} ; \mathrm{K}=$

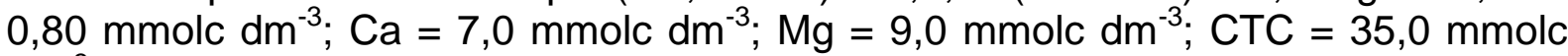
$\mathrm{dm}^{-3}$ e V (\%): 48.

O delineamento experimental utilizado foi em blocos ao acaso, com os tratamentos em esquema fatorial $4 \times 2$, correspondendo a quatro densidades de semeadura $\left(1,2,3\right.$ e $4 \mathrm{~g} \mathrm{~m}^{-2}$ de sementes), e dois direcionamentos no canteiro (Norte-Sul, Leste-Oeste) com três repetições, totalizando 24 observações. A variedade de coentro plantada foi a Verdão, e a semeadura foi em fluxo continuo de forma manual. Foram erguidos três canteiros de um metro de largura por oito metros de comprimento e 0,4 metro de altura cada, utilizando como ferramenta a enxada. Foi realizada adubação orgânica no canteiro com 1,5 litro $\mathrm{m}^{-2}$ de esterco curtido. As parcelas foram compostas por cinco fileiras com um metro de comprimento cada, e espaçamento de 0,20 metro entre as fileiras. Como área útil foram utilizadas as três 
fileiras centrais, sendo eliminadas, a título de bordadura, 0,25 metro de cada extremidade.

Durante a condução do experimento foram efetuadas capinas manuais e irrigações diárias com sistema de micro-aspersão. Por ocasião da colheita, 40 dias após a semeadura (DAS), foram realizadas as seguintes determinações: altura das plantas, medida com auxílio de régua graduada em milímetros a partir do nível do solo até a extremidade das folhas mais altas; número de plantas por metro quadrado (NP), fitomassa ou massa fresca da parte área (MFPA); produtividade ou massa fresca da parte aérea por metro quadrado e massa fresca de raízes por metro quadrado (MFR), utilizando-se balança semi-análitica de precisão para três casas decimais em gramas.

O número de plantas contido em cada parcela útil foi quantificado, sendo obtidos os valores de plantas por metro quadrado. A análise estatística dos dados foi realizada com auxílio do programa SISVAR 5.3 (FERREIRA, 2011). Os resultados foram submetidos a análise de variância e as variáveis que apresentaram diferença significativa foram avaliadas pelo teste de Tukey a $5 \%$ para o fator exposição das fileiras, enquanto que a densidade de sementes foram avaliadas por meio de análise de regressão para seleção do modelo com maior expoente significativo.

\section{RESULTADOS E DISCUSSÃO}

Para todas as variáveis em estudo não houve efeito significativo para a interação (posição no canteiro $x$ densidade de sementes). Ao analisar cada fator individualmente, verifica-se na tabela 1, que a MFR não sofreu influência de nenhum dos fatores, a posição no canteiro interferiu significativamente na massa fresca da parte aérea $(P<0,05)$ e na altura das plantas $(P<0,01)$, com a posição Norte-sul apresentando maior média $(24,42 \mathrm{~cm})$. Esse valor aproxima-se ao encontrado por Santos et al. (2019), avaliando o cultivo consorciado de alface, cebolinha e coentro, observaram maior desempenho na altura das plantas de coentro no plantio solteiro $(26 \mathrm{~cm})$.

A luz tem grande influência sobre o crescimento e produção de fitomassa, o melhor aproveitamento da radiação solar e da maior eficiência de transporte de fotossintatos para a parte aérea que para as raízes nas linhas norte-sul pode ser responsável pelo maior desempenho na altura das plantas e na massa fresca da parte aérea, resultando em melhor produção. Entretanto as linhas no sentido nortesul causam sombreamento, já que pela manhã as plantas estão expostas ao sol pelo lado leste das fileiras e, à tarde, pelo lado oeste. Neste sentido, a maior altura das plantas, quando não acompanhadas do aumento na fitomassa, pode ser devido a um estiolamento induzido pelo sombreamento, quando isso ocorre não representa que houve desempenho na produtividade. Hirata e Hirata (2015), ao avaliarem o desempenho produtivo do agrião d'água cultivado em solo sob telas de sombreamento observaram que as plantas sob as telas apresentaram alturas médias de 25,6 cm enquanto as de pleno sol $13,7 \mathrm{~cm}$. 
TABELA 1. Síntese da análise de variância, análise de regressão e do teste de médias para as variáveis Altura de plantas, número de plantas por metro quadrado, massa da parte aérea, massa da parte aérea por metro quadrado e massa de raízes por metro quadrado.

\begin{tabular}{|c|c|c|c|c|c|}
\hline \multirow{2}{*}{$\begin{array}{l}\text { Fatores de } \\
\text { Variação }\end{array}$} & \multicolumn{5}{|c|}{ Valores de $\mathrm{F}$} \\
\hline & Altura & $\begin{array}{c}\mathrm{N}^{\mathrm{a}} \mathrm{de} \\
\text { plantas } / \mathrm{m}^{2}\end{array}$ & $\begin{array}{l}\text { Massa da } \\
\text { parte } \\
\text { aérea }\end{array}$ & $\begin{array}{l}\text { Massa da } \\
\text { parte aérea } \\
/ \mathrm{m}^{2}\end{array}$ & $\begin{array}{l}\text { Massa de } \\
\text { raiz } / \mathrm{m}^{2}\end{array}$ \\
\hline Posição (P) & $16,55^{\star \star}$ & $0,01^{\mathrm{NS}}$ & $4,46^{*}$ & $0,23^{N S}$ & $0,49^{N S}$ \\
\hline $\begin{array}{l}\text { Densidade de } \\
\text { Sementes (D) }\end{array}$ & $0,22^{\mathrm{NS}}$ & $3,73^{*}$ & $4,81^{* *}$ & $0,40^{N S}$ & $1,72^{N S}$ \\
\hline PxD & $0,51^{\mathrm{NS}}$ & $1,14^{\mathrm{NS}}$ & $2,40^{N S}$ & $0,40^{N S}$ & $0,62^{N S}$ \\
\hline \multirow[t]{2}{*}{$\mathrm{CV} \%$} & 11,97 & 43,74 & 31,04 & 22,23 & 23,44 \\
\hline & \multicolumn{5}{|c|}{ Analise de regressão para Gramas de Sementes } \\
\hline Linear & $0,19^{N S}$ & $10,54^{\star *}$ & $13,84^{\star *}$ & $0,63^{N S}$ & $3,76^{\mathrm{NS}}$ \\
\hline \multirow[t]{2}{*}{ Quadrada } & $0,05^{\mathrm{NS}}$ & $0,59^{N S}$ & $0,49^{N S}$ & $0,05^{N S}$ & $0,56^{N S}$ \\
\hline & \multicolumn{5}{|c|}{ Teste médias de tukey $(\mathrm{p}<0,05)$} \\
\hline Posição & $--\mathrm{cm}--$ & -- Unid -- & ---- & $---\mathrm{g}--$ & $\overline{----}$ \\
\hline Norte-Sul & $24,42 \mathrm{a}$ & $183,46 a$ & $2,56 a$ & $1750 a$ & $654,57 a$ \\
\hline Leste-Oeste & $20,00 \mathrm{~b}$ & $187,54 a$ & $1,95 \mathrm{a}$ & $1829 a$ & $700,01 \mathrm{a}$ \\
\hline
\end{tabular}

Médias seguidas pela mesma letra minúscula na coluna não diferem entre si pelo teste de Tukey a $5 \%$ de probabilidade. ${ }^{* *}$ : significativo $(\mathrm{P}<0,01)$; ${ }^{*}$ : significativo $(\mathrm{P}<0,05)$; NS: não significativo; CV\%: coeficiente de variação.

$\mathrm{Na}$ análise de regressão para a variável NP, o modelo linear crescente foi o que melhor se ajustou (FIGURA 1). Percebe-se que a densidade populacional (número de plantas), para o intervalo observado, aumenta proporcionalmente à densidade de semeadura. O maior número de plantas por área pode proporcionar maior rentabilidade ao produtor visto que os molhos comerciáveis de coentro devem ter em média 20 plantas. Entretanto é possível que cultivos muito adensados prejudiquem o ganho de massa de cada planta. Quando o número de plantas aumenta por unidade de área, atinge-se um ponto no qual as plantas competem por fatores essenciais de crescimento, como nutrientes, luz e água (HARMS et al., 2015). 


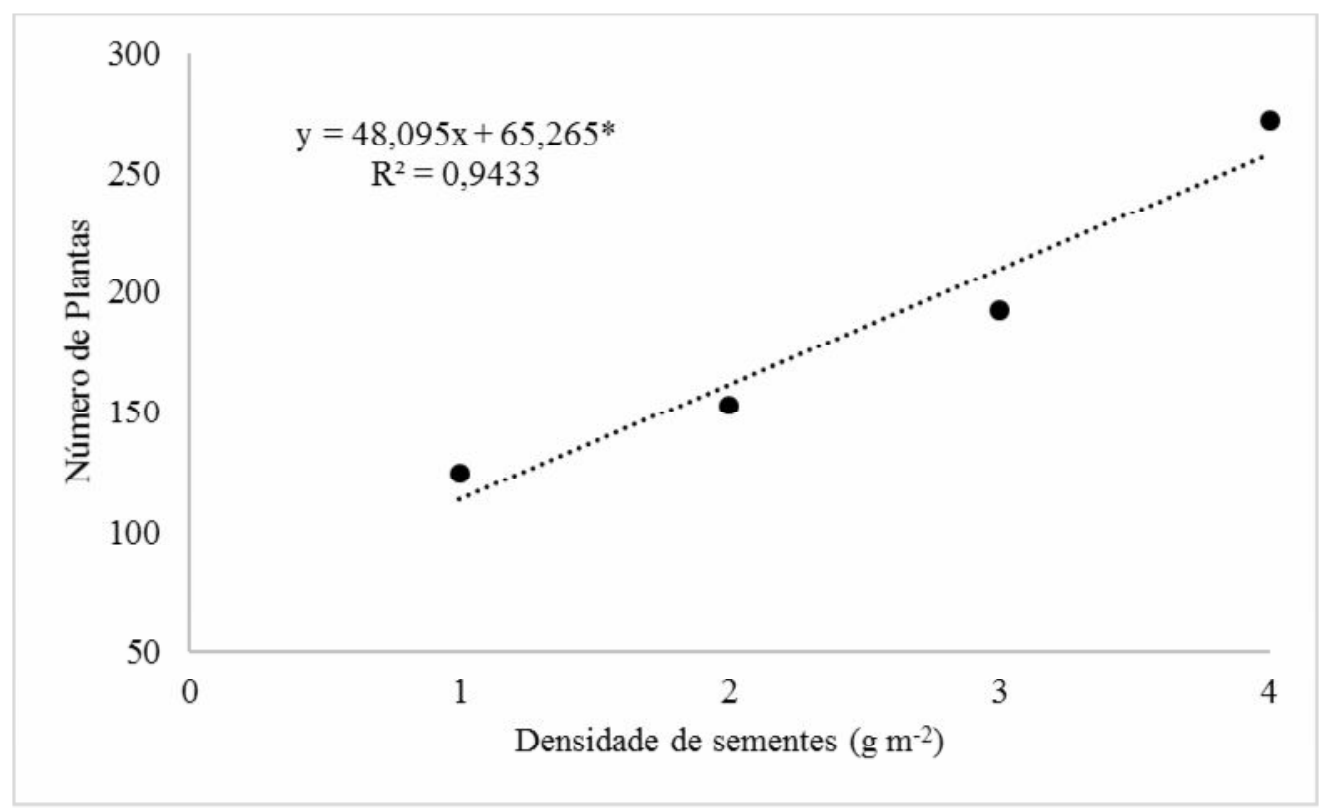

FIGURA 1. Análise de regressão para a variável número de plantas por metro quadrado

A massa fresca da parte aérea foi estatisticamente significativa tanto para o fator posição $(P<0,05)$ quanto para a densidade de semeadura $(P<0,01)$. Observa-se na análise de regressão para a variável massa da parte aérea (figura 2) que existe uma alta correlação $\left(R^{2}=0,96\right)$ entre a MFPA e a densidade de semeadura, à medida que aumenta-se a quantidade de sementes plantadas por metro quadrado a MFPA diminui, devido ao aumento na população de plantas interferir na quantidade de água, luz e nutrientes utilizados pela cultura, prejudicando o desenvolvimento.

O coentro é uma cultura que se adapta bem em cultivos com alta densidade de plantas (SILVA et al., 2016). Embora a massa da parte aérea diminua proporcionalmente ao aumento da densidade (Figura 2), a quantidade total de massa fresca produzida por metro quadrado não apresentou diferença estatística (Tabela 1). Segundo Lima et al. (2007) tal fato revela que à medida que a densidade populacional aumenta, dentro de determinados limites, há uma tendência em elevar a produção total por área, podendo resultar em maior rentabilidade para o produtor. Em cultivos mais adensados a produtividade está mais relacionada com o maior número de plantas $/ \mathrm{m}^{2}$ do que com o ganho de massa de cada planta. 


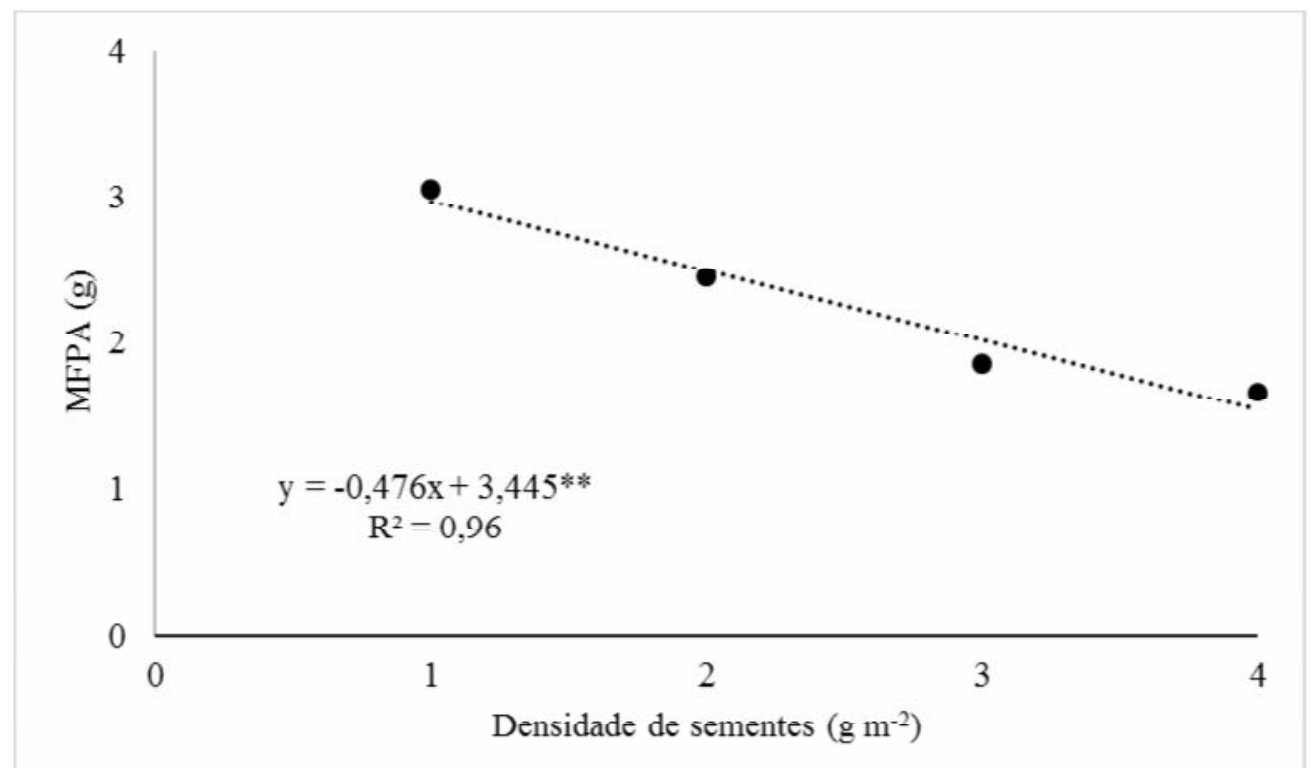

FIGURA 2. Análise de regressão para a variável massa fresca da parte aérea (MFPA)

\section{CONCLUSÕES}

A densidade de semeadura mostrou-se efetiva no ganho de massa fresca da parte aérea, entretanto para a quantidade de sementes em estudo não mostrou diferença na produtividade de massa fresca da parte aérea por metro quadrado.

O direcionamento das linhas de cultivo no canteiro no sentido norte-sul mostrou ser mais vantajoso para obter plantas com maior altura e maior quantidade de massa fresca da parte aérea, entretanto mais estudos são necessários para comprovar seu efeito no incremento da produtividade do coentro.

\section{REFERÊNCIAS}

BOMFIM, J.M.F. Pegada hídrica e desempenho econômico da cultura do coentro (Coriandrum sativum L.) no agreste sergipano. Dissertação (Mestrado em Desenvolvimento e Meio Ambiente) - Universidade Federal de Sergipe, 2017. Disponível em: <https://ri.ufs.br/handle/riufs/4251>

BORGES, L.S.; PEREIRA. M.C.; CRUZ, M.V.; GONÇALVES, C.J.B.; MELO FILHO, D.; SILVA, C.H.S.; RIBEIRO, D.P. Cultivo Consorciado de alface, cebolinha e coentro na Amazônia Tocantina/Consorciado cultivation of lettuce, chives and coriander in the Amazon Tocantina. Brazilian Journal of Development, v. 5, n. 6, p. 6092-6106, 2019. Disponível em: <https://doi.org/10.34117/bjdv5n6-120>. doi:10.34117/bjdv5n6120

FERREIRA JUNIOR, R.A.; SOUZA, J.L.; TEODORO, I.; LYRA, G.B.; SOUZA, R.C.; ARAÚJO NETO, R.A. Eficiência do uso da radiação em cultivos de milho em Alagoas. Revista Brasileira de Engenharia Agricola Ambiental, v. 18, n. 3, p. 322328, $2014 . \quad$ Disponível em: <http://www.agriambi.com.br/revista/v18n03/v18n03a12.pdf>

FERREIRA, D.F. Sisvar: A computer statistical analyssis system. Ciência e Agrotecnologia, v.35, n.6, p.1039-1042, 2011. Disponível em: < 
http://www.scielo.br/scielo.php?pid=S1413-

$70542011000600001 \&$ script=sci_arttext\&t|ng=pt>

HARMS, M. G.; PRIA, M.D.; REZENDE. B.L.A.; PRESTES, A.M.C.; DALAZOANA, F. Effects of plant density and fungicide application on foliar diseases and onion yield. Horticultura Brasileira, v. 33, n. 2, p. 203-207, 2015. Disponível em: http://dx.doi.org/10.1590/S0102-053620150000200011

HIRATA, A.C.S.; HIRATA, E.K. Desempenho produtivo do agrião d'água cultivado em solo sob telas de sombreamento. Pesquisa Agropecuária Brasileira, v. 50, n. 10, p. 895-901, $2015 . \quad$ Disponível em: <http://seer.sct.embrapa.br/index.php/pab/article/view/21651/13084>

KAPPES, C. Desempenho de híbridos de milho em diferentes arranjos espaciais de plantas. Dissertação (Curso de Pós Graduação em Agronomia Sistemas de Produção) - Faculdade de Engenharia de Ilha Solteira, 2010. Disponível em:

$<\mathrm{https}$ ://repositorio.unesp.br/bitstream/handle/11449/98758/kappes_c_me_ilha.pdf;js essionid=2839965B521BD5B2F48B16C69371F126?sequence=1>

KOEPPEN, W. Climatologia: con un estudio de los climas de la tierra. 1948.

LIMA, J.S.S.; BEZERRA NETO, F.; NEGREIROS, M.Z.; FREITAS, K.K.C.; BARROS JUNIOR, A.P. Desempenho agroeconômico de coentro em função de espaçamentos e em dois cultivos. Revista Ciência Agronômica, v. 38, n. 4, p. 407-413, 2007. Disponível em:<http://ccarevista.ufc.br/seer/index.php/ccarevista/article/view/102>

LOPES, A.; TEIXEIRA, D.; CALHAU, C.; PESTANA, D.; PADRÃO, P.; GRAÇA, P. Ervas aromáticas: uma estratégia para a redução de sal na alimentação dos portugueses. Programa Nacional para a Promoção da Alimentação Saudável, 2015. Disponível em: <https://repositorioaberto.up.pt/bitstream/10216/82620/2/116245.pdf>

MACIEL, G.M.; COSTA, C.P.; SALA, F.C. Linhagens de coentro com pendoamento tardio sob dois sistemas de plantio. Horticultura Brasileira, v. 30 n. 1, p. 607-612, 2012. Disponível em: http://dx.doi.org/10.1590/S0102-05362012000400008.

PEREIRA, S. R.; MARLOVE M.F.B.; NASCIMENTO, W.M. Aspectos relacionados à qualidade de sementes de coentro. Embrapa Hortaliças-Artigo em periódico indexado (ALICE), 2005.2 Disponível em: <http://www.scielo.br/pdf/hb/v23n3/a02v23n3>

RESENDE, G.M.; COSTA, N.D.; YURI, J.P.; FERREIRA, J.C.; MOTA, J.H. Densidade de plantio na cultura da cenoura no Submédio do Vale do São Francisco. Scientia $\begin{array}{lllllll}\text { Plena, } & \text { v. } & 12, & \text { n. } & 4, & 2016 . & \text { Disponível em: }\end{array}$ <https://www.scientiaplena.org.br/sp/article/view/2878>. doi: 10.14808/sci.plena.2016.040202

SILVA, J.M.; CHALCO, F.P. Coleções didáticas de sementes de hortaliças. 2017. Disponível em: <http://repositorioinstitucional.uea.edu.br/handle/riuea/653> 
SILVA, J.M.F.; PINTO, A.A.; SANTANA, L.D.; RODRIGUES, W.A.D.; CAMARA, F.T. Produtividade do coentro verdão em função das regulagens de uma semeadora manual. Enciclopédia Biosfera, Centro Cientifico Conhecer - Goiânia, v.13 n.24; p. 854 , 2016.

Disponível

em: $<$ http://www.conhecer.org.br/enciclop/2016b/agrarias/produtividade\%20do\%20coentr o.pdf>. doi: 10.18677/EnciBio_2016B_080 